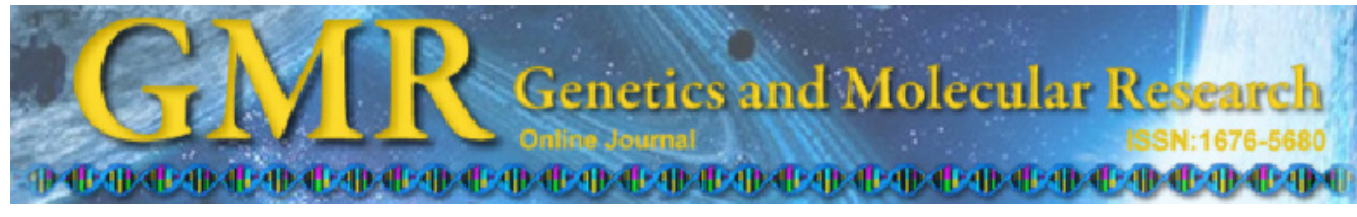

\title{
Efficient identification of ornamental peach cultivars using RAPD markers with a manual cultivar identification diagram strategy
}

\author{
J. Han ${ }^{1}$, W.Y. Wang ${ }^{1}$, X.P. Leng ${ }^{1}$, L. Guo ${ }^{2}$, M.L. Yu ${ }^{2}$, W.B. Jiang ${ }^{1}$ and \\ R.J. $\mathrm{Ma}^{2}$ \\ ${ }^{1}$ College of Horticulture, Nanjing Agricultural University, Nanjing, China \\ ${ }^{2}$ Institute of Horticulture, Jiangsu Academy of Agricultural Sciences, Nanjing, \\ China \\ Corresponding authors: M.L. Yu / W.B. Jiang \\ E-mail: fangjingui@hotmail.com / weibingj@sohu.com
}

Genet. Mol. Res. 13 (1): 32-42 (2014)

Received October 31, 2013

Accepted November 30, 2013

Published January 8, 2014

DOI http://dx.doi.org/10.4238/2014.January.8.2

\begin{abstract}
One of the most important uses of DNA markers is cultivar identification. However, no DNA fingerprint analysis strategy is available for making DNA markers helpful in practical plant cultivar identification, especially for the identification of a large number of cultivars. We developed a manual cultivar identification diagram strategy for efficient identification of plant cultivars, from which a cultivar identification diagram (CID) of genotyped plant individuals can be constructed manually. This CID could be used as a reference for quick identification of plant cultivars of interest. We used 11-mer RAPD primers to amplify DNA samples of 32 ornamental peach genotypes; all the cultivars were well distinguished by fingerprints from 6 primers. The utility of this CID was verified by identification of three randomly chosen groups of cultivars among the 32 ones that we selected. This CID generated will be useful for the identification of commercially important ornamental peach cultivars.
\end{abstract}

Key words: Ornamental peach; RAPD; Cultivar identification; Molecular markers 


\section{INTRODUCTION}

Peach (Prunus persica L.) is one of the most economically important fruit crops. As the center of origin of peaches, China has the most abundant resources of both wild and cultivated varieties (Yuan et al., 2002; Yang et al., 2002), including those with high ornamental value for colorful flower and/or leaves. Ornamental peach trees have also been cultivated in China for thousands of years (Everett, 1967; Hu and Zhang, 2005). The flowers are produced in early spring before the leaves; they are solitary or paired, pink, with 1 or 7 several whorls of petals. All these characteristics make ornamental peach an excellent plant for urban landscapes and gardens. However, scientific research on genetics and molecular biology has only focused on the peach trees cultivated for fruit. This demands more research focused on the genetics and molecular biology of ornamental peach, including accurate identification of ornamental peach varieties and genotypes that are important for the ornamental peach nursery and peach industry.

Traditionally, identification of the plant was based on morphological or physiological aspects. Biochemical markers such as isoenzymes have been used but they have many drawbacks, including the limited number of polymorphisms detected between close cultivars and variations due to the physiological stage. Even though several generations of DNA markers have been developed and used for cultivar identification and genetic analysis, leading to the publication of thousands of papers, no efficient approach has been developed and used to make DNA markers useful in cultivar identification, besides the phylogenetic trees and/ or some fingerprints employed in identification on a very small scale. Phylogenetic trees cannot tell us which primer to use and the information to use or refer to for specific cultivar identification, while traditional fingerprinting does not present all the fingerprints together and is thus not ideal for the identification of many cultivars.

Various DNA-based markers have recently been developed and used for studies on genetic diversity, fingerprinting and cultivar origins (D'Onofrio et al., 2009; Melgarejo et al., 2009; Cheng and Huang, 2009; Elidemir and Uzun, 2009; Papp et al., 2010). Random amplified polymorphic DNA (RAPD) markers have been proven to be a reliable marker system for genetic fingerprinting and also in determining the genetic relationships between germplasm collections. RAPD markers have the advantage of being simple, able to detect relatively small amounts of genetic variation and not needing prior information on the genome. The technique has already been successfully applied to estimate genetic relationships in litchi (Ding et al., 2000), apple (Stark-Urnau, 2002a), apricot (Mariniello et al., 2002), Indian cashew (Archak et al., 2003), olive (Belaj et al., 2003), mulberry (Vijayan, 2004), pear (Stark-Urnau, 2002b; Lee et al., 2004), grape (Benjak et al., 2005), fig (Sadder and Ateyyeh, 2006), longan (Yonemoto et al., 2006), and cherry (Demirsoy et al., 2008). The optimization of the RAPD technique, by choosing 11 nucleotide primers and strict screening of PCR annealing temperature before being employed in fingerprinting plants, can make RAPD a preferable technique for use in plant cultivar identification.

With the strategy of manual cultivar identification diagram (MCID), a new analysis strategy of DNA fingerprints in generating referable information showing specific primers and polymorphic markers that could be used to separate and identify cultivars (Li et al., 2011; Zhang et al., 2011; Zhao et al., 2011; Korir et al., 2012), it is much more feasible to carry out efficient identification of plant individuals. This new way of recording DNA fingerprints of genotyped plants can generate a cultivar identification diagram (CID) to be used as a source of referable information for quick identification of plant and/or seed samples in the future. 
Based on the necessity of ornamental peach cultivar identification and the advantages of MCID in applying DNA markers in plant identification, the identification of 32 commercially important ornamental peach cultivars was carried out using RAPD banding patterns.

\section{MATERIAL AND METHODS}

\section{Plant materials}

Young leaves of 32 selected ornamental peach cultivars were collected from the Jiangsu Academy of Agricultural Science, Nanjing, China. The names and main ornamental characters of these cultivars are shown in Table 1, and some representative cultivars are shown in Figure 1.

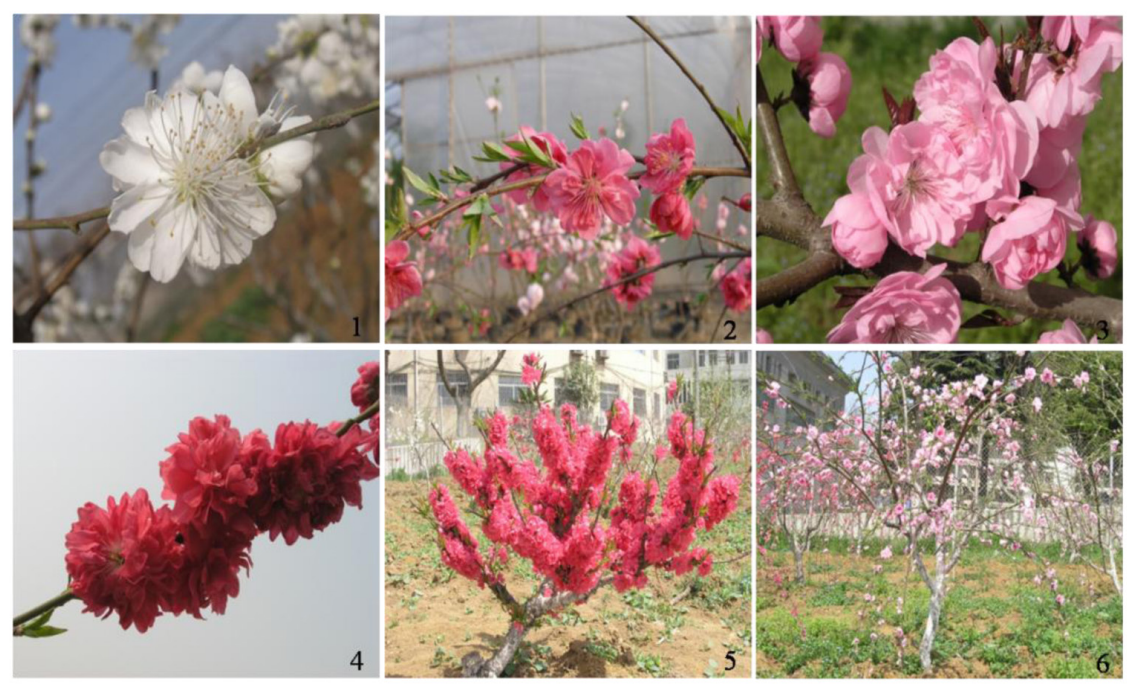

Figure 1. Six representative ornamental peach cultivars. 1-6 = 'bai hua bi tao', 'F2 chui zhi', 'Hong fen jia ren', 'Fei tao', 'Hong shou', 'Zhu fen chui zhi', respectively.

\section{Genomic DNA extraction}

Total genomic DNA of each genotype was extracted from young leaves using the modified cetyltrimethylammonium bromide (CTAB) method (Murray and Thompson, 1980; Fang et al., 2006). The extracted DNA was diluted to a final concentration of $30 \mathrm{ng} / \mu \mathrm{L}$ with $1 \mathrm{X}$ TE buffer and stored at $-20^{\circ} \mathrm{C}$ pending use.

\section{RAPD analysis}

In case of RAPD reactions, 54 primers were initially tested with a few genotypes, and only those primers resulting in clear unambiguous banding patterns with all genotypes tested were selected for use in genotyping the full set of cultivars. 
Fifty-four 11-mer RAPD primers were used for screening in this study. To increase credibility of the fragments, we used only those primers resulting in clear unambiguous banding patterns. Subsequently, 6 primers (Table 2) that showed well-resolved and reproducible bands were selected to assay all genotypes. Reaction solutions consisted of $2.0 \mu \mathrm{L} 10 \mathrm{X}$ buffer, $1.2 \mu \mathrm{L} 25 \mathrm{mM} \mathrm{MgCl}_{2}, 1.6 \mu \mathrm{L} 2.5 \mathrm{mM}$ dNTP, $1.6 \mu \mathrm{L} 1.0 \mu \mathrm{M}$ primer, $0.1 \mu \mathrm{L} 5 \mathrm{U} / \mu \mathrm{L}$ rTaq Polymerase Dynazyme, and $1 \mu \mathrm{L}$ genomic DNA, making a total volume of $20 \mu \mathrm{L}$. Amplification reactions were performed based on the standard protocol of Williams et al. (1990), with minor modifications (Wang et al., 2011). PCR was carried out in an Autorisierter Thermocycler (Eppendorf, Hamburg, Germany), programmed as follows: an initial predenaturation step for $5 \mathrm{~min}$ at $94^{\circ} \mathrm{C}$; then 42 cycles each consisting of a denaturation step for $30 \mathrm{~s}$, an annealing step for $1 \mathrm{~min}$ at annealing temperature (Table 2) and an extension step for $2 \mathrm{~min}$ at $72^{\circ} \mathrm{C}$. Amplification was terminated by a final extension of at $72^{\circ} \mathrm{C}$ for $10 \mathrm{~min}$. After amplification, the amplified DNA fragments were separated by gel electrophoresis on $1.3 \%$ agarose $(\mathrm{w} / \mathrm{v})$ (Figure 2) in 1X TAE buffer (0.04 M Tris-acetate, $0.001 \mathrm{M} \mathrm{EDTA,} \mathrm{pH} \mathrm{8.0)} \mathrm{at} 100 \mathrm{~V}$. The gels were stained with $0.5 \mu \mathrm{g} / \mathrm{mL}$ ethidium bromide and visualized under ultraviolet light for polymorphic bands among the cultivars. All amplifications were repeated separately at least thrice to obtain reproducible, accurate and clear banding patterns.

\section{Data analysis}

Only clear unambiguous bands in the photographic prints of gels were chosen and scored for cultivar identification. Where some cultivars had a specific band in the fingerprint generated from one primer, they could be separated singly, and those cultivars sharing the same banding pattern were separated into the same sub-group. Based on this strategy, all the ornamental peach cultivars were gradually and completely separated from one another as more primers were employed.

\section{Test of the utilization and workability of the CID}

Three groups of ornamental peach cultivars, randomly chosen from the inter- and intragroups, were used to verify the utilization and workability of the diagram showing the separation of the 32 cultivars. The three groups of cultivars were marked "A", "B" and "C", and the corresponding primers to be used for separation of each group were easily picked out from the diagram. If the randomly chosen cultivars could be distinguished accurately and quickly as anticipated on the whole cultivar identification diagram, it would definitely give assurance that the strategy developed and employed in this study is scientific, workable, and efficient, consequently making this method an ideal way to use molecular markers for the identification of fruit crop cultivars and seed samples of field crops. The data from the cultivar separation in the cultivar identification diagram can also be provided in a database for ease of reference.

\section{RESULTS}

\section{Cultivar identification}

To establish a stable and optimistic RAPD system with high reproducibility, longer 
primers (11 nucleotides) were employed and the annealing temperature for each primer was screened based on the quality and reproducibility of banding patterns. The primers were randomly screened from a stock of 54 11-mer primers, and once an optimistic primer that could produce reproducible polymorphic bands was screened, it was further utilized in the identification of the ornamental peach cultivars. By the time the 11th primer was (Table 2) screened and utilized, all 32 ornamental peach cultivars could be successfully identified. An example of the RAPD patterns in the study included that obtained using primer Y29 (Figure 2 ), which was also the first primer used to amplify the 32 ornamental peach cultivars. The electrophoresis results showed that primer Y29 generated uniform, clear, and reproducible band patterns in 7 ornamental peach cultivars assigned lane number codes 1, 7, 12, 22, 24, 25 , and 26 (the lane numbers corresponding to the cultivar names are shown in Table 1). This group of 7 ornamental peach cultivars was easily differentiated from the other two groups by the presence and/or absence of distinct 700- and 250-bp bands. Another group with 2 ornamental peach cultivars was then assigned lane number codes 17 and 29 by the presence of a 1200-bp band; the polymorphic bands with sizes of 700-, 250-, 1200-bp were chosen to separate the 32 cultivars, and the presence and/or absence of the three bands could classify these cultivars into four groups as shown in the diagram (Figure 3). Five other primers (Table 2) were, step by step, screened and chosen to differentiate the ornamental peach cultivars until full separation was achieved as shown in Figure 3. For example, the second primer used (Y6) could further separate the four groups of cultivars, earlier identified by primer Y29, into smaller groups. Other primers were chosen to differentiate the several subgroups of ornamental peach cultivars. The group of 11 cultivars assigned the lane number codes $3,4,5,8,9,10,13,18,27,28$, and 32 , could be separated with band sizes of about 850 and 260 bp by primer Y6 (Figure 4). Afterwards, the ornamental peach cultivars could still be separated into many more groups, and following this method systematically and utilizing 6 primers, all 32 ornamental peach cultivars could eventually be differentiated from each other.

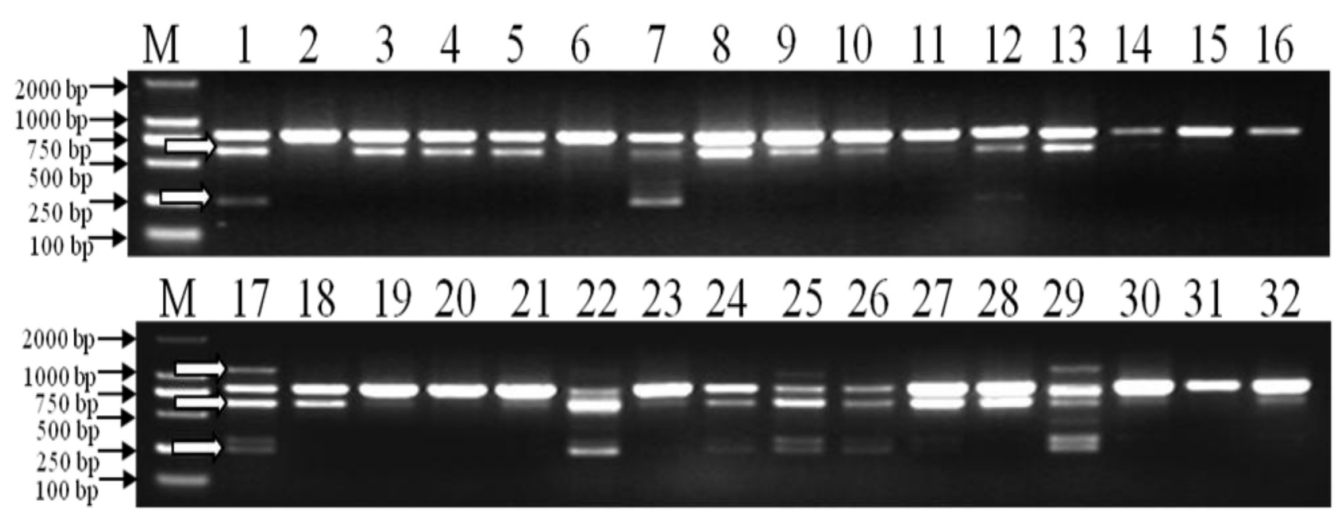

Figure 2. DNA banding patterns of 32 ornamental peach cultivars amplified by primer Y29. Lane $M=$ DL2000 plus DNA ladders; lanes 1 to $32=$ accession numbers of ornamental peach cultivars listed in Table 1 . 
Table 1. Name of the materials used in the experiment.

\begin{tabular}{|c|c|c|c|c|c|}
\hline No. & Name & Branch type or tree type & Leaf color & Petal color & Petal type \\
\hline 1 & Hongfenjiaren & Straight-stem & Purple & Pink & Double-whirl petal \\
\hline 2 & Hua 6 & Straight-stem & Green & Pink & Double-whirl petal \\
\hline 3 & Fenrousebitao & Straight-stem & Green & Pink & Double-whirl petal \\
\hline 4 & Taohuan2hao & Straight-stem & Green & Pink & Double-whirl petal \\
\hline 5 & Juhuatao & Straight-stem & Green & Pink & Double-whirl petal \\
\hline 6 & F2 chuizhi & Pendulous-stem & Green & Red & Double-whirl petal \\
\hline 7 & Hua 2 & Pendulous-stem & Green & Pink & Double-whirl petal \\
\hline 8 & Yuanyangchuizhi & Pendulous-stem & Green & Mottle & Double-whirl petal \\
\hline 9 & Danbanzitao & Straight-stem & Purple & Pink & Single-whirl petal \\
\hline 10 & Danbanbaishou & Dwarf & Green & White & Single-whirl petal \\
\hline 11 & Dan ban bai hua & Straight-stem & Green & White & Single-whirl petal \\
\hline 12 & Wubao & Straight-stem & Green & Mottle & Double-whirl petal \\
\hline 13 & Huangjinmeili & Straight-stem & Green & Pink & Double-whirl petal \\
\hline 14 & Tanchun & Straight-stem & Green & Pink & Double-whirl petal \\
\hline 15 & Taohua1hao & Straight-stem & Green & Red & Double-whirl petal \\
\hline 16 & Yingchun & Straight-stem & Green & Pink & Double-whirl petal \\
\hline 17 & Hongbaichuizhi & Pendulous-stem & Green & Mottle & Double-whirl petal \\
\hline 18 & Baibitao & Straight-stem & Green & White & Double-whirl petal \\
\hline 19 & Mantianhong & Straight-stem & Green & Red & Double-whirl petal \\
\hline 20 & Hua 5 & Straight-stem & Green & Pink & Double-whirl petal \\
\hline 21 & F1 chuizhi & Pendulous-stem & Green & Red & Double-whirl petal \\
\hline 22 & Feitao & Straight-stem & Green & Red & Double-whirl petal \\
\hline 23 & Baihuashanbitao & Straight-stem & Green & White & Double-whirl petal \\
\hline 24 & Hua 3 & Straight-stem & Green & Pink & Double-whirl petal \\
\hline 25 & Hongshou & Dwarf & Green & Red & Double-whirl petal \\
\hline 26 & Baibitao 1 & Straight-stem & Green & White & Double-whirl petal \\
\hline 27 & Honghuabitao & Straight-stem & Green & Red & Double-whirl petal \\
\hline 28 & Zhufenchuizhi & Pendulous-stem & Green & Pink & Double-whirl petal \\
\hline 29 & Yi zheng chi zhi & Pendulous-stem & Green & Mottle & Double-whirl petal \\
\hline 30 & Chui zhi tao & Pendulous-stem & Green & Red & Double-whirl petal \\
\hline 31 & Hongchuizhi & Pendulous-stem & Green & Red & Double-whirl petal \\
\hline 32 & Dan ban hong shou & Dwarf & Green & Red & Single-whirl petal \\
\hline
\end{tabular}

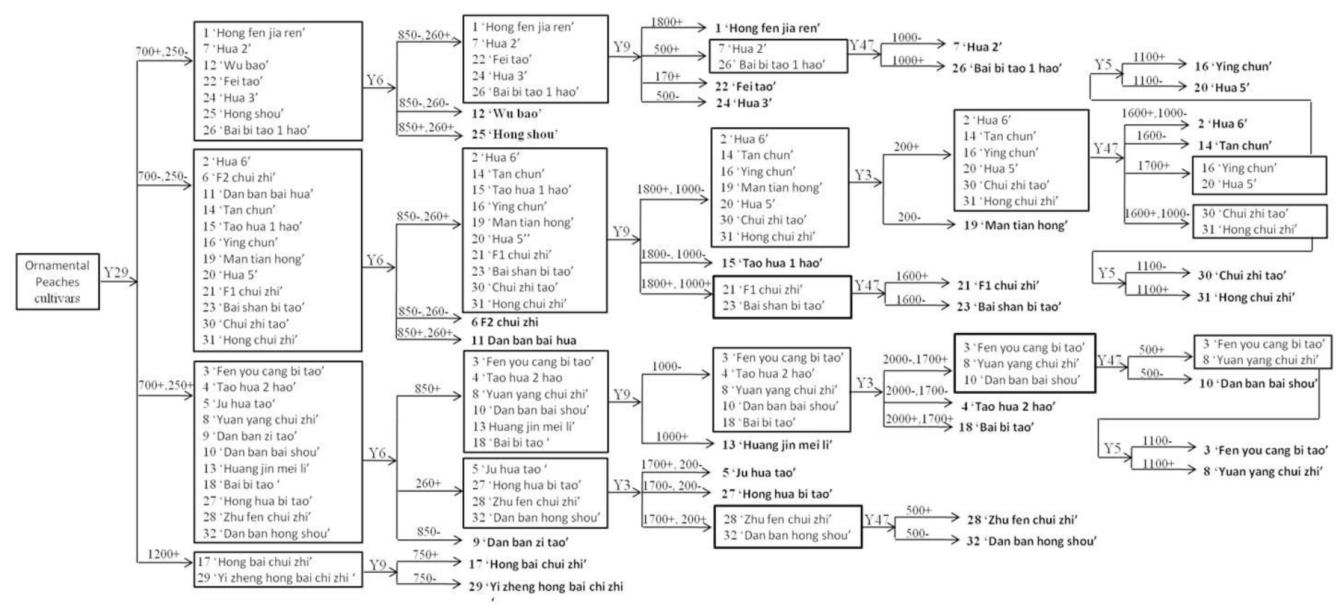

Figure 3. Cultivar identification diagram of the ornamental peach cultivars by 6 primers. The numbers above each horizontal line in the diagram were the size (in $\mathrm{bp}$ ) of the polymorphic bands used to separate the cultivars following the line $(+)$ = presence of the polymorphic band; $(-)=$ absence of it. The cultivars name in bold fonts are those that were separated. 
Table 2. Six primers chosen for further fingerprinting of the 32 ornamental peach genotypes.

\begin{tabular}{lcc}
\hline Primer & Nucleotide sequence $\left(5^{\prime}-3^{\prime}\right)$ & Annealing temperature $\left({ }^{\circ} \mathrm{C}\right)$ \\
\hline Y-3 & GTTTCGCTCCA & 44.7 \\
Y-5 & GTTTCGCTCCG & 43.7 \\
Y-6 & GTTTCGCTCCC & 44.4 \\
Y-9 & CTGCTGGGACA & 41.7 \\
Y-29 & GTGTGCCCCAG & 42.8 \\
Y-47 & ACGACCGACAG & 43.7 \\
\hline
\end{tabular}

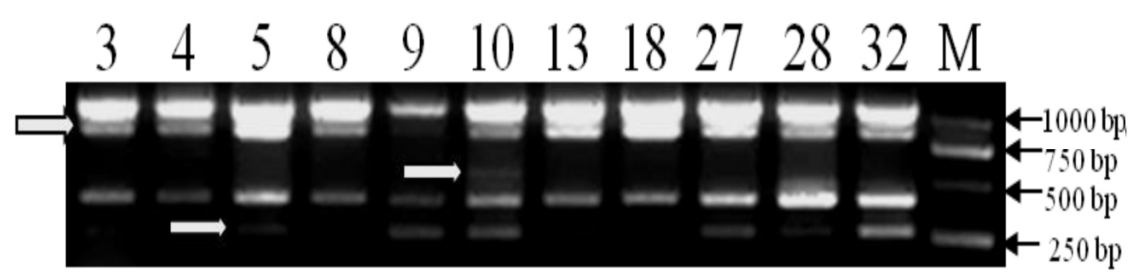

Figure 4. DNA banding patterns of 11 ornamental peach cultivars in group from the separation of primer Y6. Lane $M=$ DL2000 plus DNA ladders. The bands pointed with larger arrows were those employed to separate the cultivars.

\section{Test of the utilization and workability of the CID}

The important aim of this study was not only to use the RAPD marker to distinguish the important 32 ornamental peach cultivars as done by most earlier reports focusing on the utilization of DNA marker in identifying plant cultivars, but also to generate a referable ornamental peach CID that could be used in practical identification of some of these cultivars in the future for the nursery industry as well as in cultivar-right-protection. With these two aims in mind, it was critical to verify the utilization, workability and efficiency of the diagram in cultivar identification. To undertake this, three groups of cultivars composed of 'Fen you cang bi tao', 'Ju hua tao', 'Yuan yang chui zhi', and 'Zhu fen chui zhi', 'Hong bai chui zhi' and 'Yi zheng hong bai chi zhi', 'F1 chui zhi' and 'Bai shan bi tao', which came from the inter- and intra-groups in the CID, were randomly chosen and used for the verification exercise. From the location of these cultivars in CID, it was easy to find the primer to use in separating them, which were the primers Y6, Y5, Y3, Y9, and Y47. Clearly, the PCR results agreed with those anticipated in the CID, in that all cultivars in these three groups were separated accordingly. The first group according to Figure 5 (A, B, C) could be validated with the three primers Y6 Y5 and Y3. The PCR results showed that four ornamental peach cultivars could first be separated into two groups by primer Y6 with a band of about 850 and $260 \mathrm{bp}$. One group composed of 'Fen you cang bi tao' and 'Yuan yang chui zhi', could be further separated with primer Y5 by a 1100-bp band. The other group of 'Ju hua tao' and 'Zhu fen chui zhi', could then be divided by the use of primer Y3 with a band of $200 \mathrm{bp}$. 'Hong bai chui zhi' and 'Yi zheng hong bai chi zhi' could be separated with a specific band of about $750 \mathrm{bp}$ with primer Y9 as in the CID. Another group of 'F1 chui zhi' and 'Bai shan bi tao' was divided by primer Y47 with a band of about $1600 \mathrm{bp}$. By this procedure, all three groups were successfully identified with a suitable combination of primers. This test therefore proved the availability, workability and efficiency of this method in ornamental peach cultivar identification. 


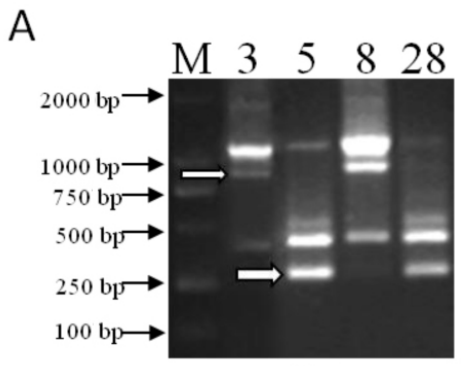

a

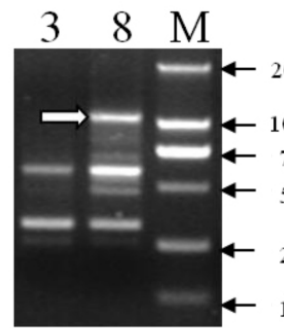

b

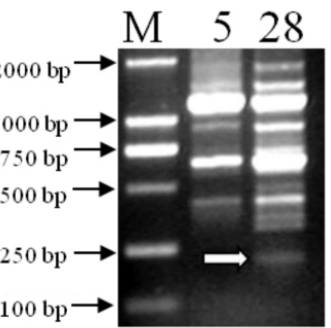

C
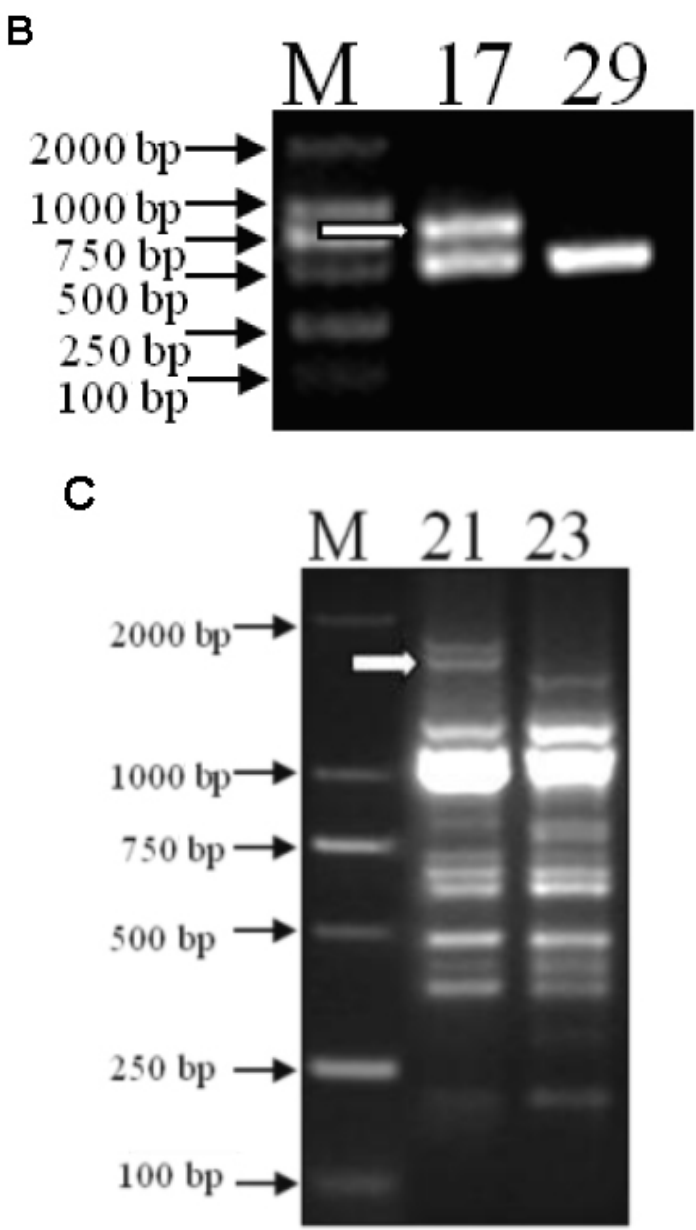

Figure 5. Result of cultivars selected randomly by the corresponding primers. Lane $M=$ DL2000 plus marker. A. Fingerprint obtained with three primers used to separate the first group of cultivars selected: "a", "b", and "c" obtained with the primers Y6, Y3, and Y5, respectively. B. Fingerprint obtained with the primer Y9 used to separate the group 'Hong bai chui zhi' and 'Yi zheng hong bai chi zhi'. C. DNA fingerprint obtained with the primer Y47 used to separate the group 'F1 chui zhi' and 'Bai shan bi tao'. 


\section{DISCUSSION}

China is an important agricultural country in the world and has abundant plant resources, which makes distinguishing of plant cultivars or varieties an important task for plant scientists. One of the ultimate purposes of plant science is to serve agriculture, and the means of practical application of new biological techniques in agricultural production are very important. Ornamental peach is an important plant for urban landscapes and gardens. Along with frequent exchange of resources between regions and the lack of management of varietal resources, background knowledge of some of these cultivars used is unclear. The name confusion, especially in nursery stock markets, is a real problem as myriad false claims of inferiority or superiority of a cultivar are not backed by any evidence. This can adversely affect future production of desired cultivars. The need to demystify science by developing strategies of applying new knowledge and technology to practical activities to solve the above problem is therefore both necessary and significant. DNA markers are a powerful technique that can be used to accurately identify plant cultivars and species, with several generations of DNA markers having been developed and used for cultivar identification (Saker et al., 2006; Chiu et al., 2010) and genetic analysis (Boronnikova et al., 2007; Silvestrini et al., 2008; Bhau et al., 2009; Baysal et al., 2010). Thousands of papers on this subject have also been published. Despite this, DNA markers have not been readily used for the genotyping of plants. In fact, the situation is much dire than anticipated, with the question of whether DNA markers can be adequately and easily used in the identification of plant varieties yielding a negative response. No efficient approach has been developed to employ DNA markers easily and efficiently in plant cultivar identification except where phylogenetic tree clusters or some fingerprints were utilized. Apparently, clusters formed in phylogenetic trees cannot tell us which information can be used for identification of the desired plant samples while fingerprinting cannot present all the fingerprints from many cultivars together for identification. The main reasons for these weaknesses can be attributed to the fact that no analysis could connect the information of DNA fingerprints with cultivars in an easy, clear and readable way. The new approach we developed to utilize DNA markers in distinguishing cultivars is both an efficient and practical one, providing less cost, quick work and clear aims, among other benefits. This strategy can realize the power of DNA markers in plant cultivar identification, and can use the polymorphic nature of each primer, gradually distinguishing and charting every species. Although the method does not accurately reflect the genetic relationship of the cultivars/species, theoretically, the first cultivars/species to be separated will have the widest genetic distance between them. The reverse of this holds true. This method definitely does help greatly in plant cultivar identification for purposes of the protection of cultivar rights, and early identification of seedlings in the nursery industry. To improve the efficiency and utilization of this strategy in the fruit crop industry, more commercially important cultivars in production were chosen for identification. If there are one or more new cultivars that need to be separated and the identification result put in the diagram, the whole set of the primers used to run the additional DNA samples can be used and a larger diagram with the identification information of the new cultivars formed. If the set of primers used originally, such as the 6 primers in this study cannot work well in the separation of new cultivars, new primers need to be screened and used. This study is not difficult or time-consuming and it deserves to be utilized in agriculture.

This is the first report on using RAPD primers in sequence to identify ornamental peach cultivars. The reliability of this identification result was also verified. In this study, the 
experimental verification yielded satisfactory results. Therefore, this experiment confirms the possibility of utilizing DNA markers even in plant species that have a highly heterozygous genome, without requiring a genetic linkage map and/or any DNA sequence information to distinguish the cultivars. The MCID strategy is not just a simple theoretical model but a truly handy one as it makes DNA markers more applicable for plant variety identification in practice.

\section{ACKNOWLEDGMENTS}

Research supported by the National Natural Science Foundation of China (\#30871681) and the China Agriculture Research System (\#CARS-31).

\section{REFERENCES}

Archak S, Gaikwad AB, Gautam D, Rao EVVB, et al. (2003). DNA fingerprinting of Indian cashew (Anacardium occidentale L.) varieties using RAPD and ISSR techniques. Euphytica 130: 397-404.

Baysal O, Siragusa M, Gumrukcu E, Zengin S, et al. (2010). Molecular characterization of Fusarium oxysporum $\mathrm{f}$. melongenae by ISSR and RAPD markers on eggplant. Biochem. Genet. 48: 524-537.

Belaj A, Satovic Z, Ismaili H, Panajoti D, et al. (2003). RAPD genetic diversity of Albanian olive germplasm and its relationships with other Mediterranean countries. Euphytic 130: 387-395.

Benjak A, Ercisli S, Vokurka A, Maletic E, et al. (2005). Genetic relationships among grapevine cultivars native to Croatia, Greece and Turkey. Vitis 44: 73-77.

Bhau BS, Medhi K, Das AP, Saikia SP, et al. (2009). Analysis of genetic diversity of Persea bombycina "Som" using RAPD-based molecular markers. Biochem. Genet. 47: 486-497.

Boronnikova SV, Kokaeva ZG, Gostimsky SA, Dribnokhodova OP, et al. (2007). Analysis of DNA polymorphism in a relict Uralian species, large-flowered foxglove (Digitalis grandiflora Mill.), using RAPD and ISSR markers. Russ. J. Genet. 43: 530-535.

Cheng ZP and Huang HW (2009). SSR fingerprinting Chinese peach cultivars and landraces (Prunus persica) and analysis of their genetic relationships. Sci. Hortic. 120: 188-193.

Chiu T-H, Pang J-C, Chen M-H and Tsen H-Y (2010). Improvement of strain discrimination by combination of RAPD with PFGE for the analysis of the swine isolates of Salmonella enterica serovar Choleraesuis. Word J. Microbiol. Biotechnol. 27: 465-469.

D’Onofrio C, Lorenzis G, de Giordani T, Natali L, et al. (2009). Retrotransposon-based molecular markers in grapevine species and cultivars identification and phylogenetic analysis. Acta Hortic. 827: 45-52.

Demirsoy L, Demir T, Demirsoy H, Kacar YA, et al. (2008). Identification of some sweet cherry cultivars grown in Amasya by RAPD markers. Acta Hortic. 795: 147-152.

Ding XD, Lu LX, Chen XJ and Guan X (2000). Identifying litchi cultivars and evaluating their genetic relationships by RAPD markers. J. Trop. Subtrop. Bot. 8: 49-54.

Elidemir AY and Uzun I (2009). Assessment of genetic diversity of some important grape cultivars, rootstocks, and wild grapes in Turkey using RAPD markers. Acta Hortic. 827: 275-278.

Everett TH (1967). New Illustrated Encyclopedia of Gardening. New York Botanical Garden Press, New York.

Fang JG, Twito T, Zhang Z and Chao CT (2006). Genetic diversity of fruiting-Mei (Prunus mume Sieb. et Zucc.) accessions revealed by AFLP and SNP markers. Genome 49: 1256-1264.

Hu DY and Zhang ZS (2005). Genetic relationship of ornamental peach determined using AFLP markers. HortScience 40: $1782-1786$.

Korir NK, Han J, Shangguan L, Wang C, et al. (2012). Plant variety and cultivar identification: advances and prospects. Crit. Rev. Biotechnol.

Lee GP, Lee CH and Kim CS (2004). Molecular markers derived from RAPD, SCAR, and the conserved 18S rDNA sequences for classification and identification in Pyrus pyrifolia and P. communis. Theor. Appl. Genet. 108: 14871491.

Li XY, Wang C, Yang G, Li XD, et al. (2011). Employment of a new strategy for identification of Prunus mume cultivars using random amplified polymorphic deoxyribonucleic acid (RAPD) markers. Afr. J. Plant Sci. 5: 500-509.

Mariniello L, Sommella MG, Sorrentino A, Forlani M, et al. (2002). Identification of Prunus armeniaca cultivars by RAPD and SCAR markers. Biotechnol. Lett. 24: 749-755. 
Melgarejo P, Martcnez JJ, Hernández Fca, Martínez R, et al. (2009). Cultivar identification using 18S-28S rDNA intergenic spacer-RFLP in pomegranate (Punica granatum L.). Sci. Hortic. 120: 500-503.

Murray MG and Thompson WF (1980). Rapid isolation of high molecular weight plant DNA. Nucleic Acids Res. 8: 43214325.

Papp N, Szilvassy B, Abranko L, Szabo T, et al. (2010). Main quality attributes and antioxidants in Hungarian sour cherries: identification of genotypes with enhanced functional properties. Int. J. Food Sci. Technol. 45: 395-402.

Sadder MT and Ateyyeh AF (2006). Molecular assessment of polymorphism among local Jordanian genotypes of common fig (Ficus carica L.). Sci. Hortic. 107: 347-351.

Saker MM, Adawy SS, Mohamed AA and El-Itriby HA (2006). Monitoring of cultivar identity in tissue culture-derived date palms using RAPD and AFLP analysis. Biol. Plant. 50: 198-204.

Silvestrini M, Maluf MP, Silvarolla MB, Guerreiro-Filho O, et al. (2008). Genetic diversity of a Coffea germplasm collection assessed by RAPD markers. Genet. Res. Crop Evol. 55: 901-910.

Stark-Urnau M (2002a). RAPD-Marker bei Malus x domestica (Apfel) und Pyrus communis (Birne) als Mittel zur Sortenidentifizierung-Teil I: Malus x domestica (Apfel). Erwerbsobstbau 44: 139-144.

Stark-Urnau M (2002b). RAPD-Marker bei Malus x domestica (Apfel) und Pyrus communis (Birne) als Mittel zur Sortenidentifizierung-Teil II: Pyrus communis (Birne). Erwerbsobstbau 44: 167-171.

Vijayan K (2004). Genetic relationships of Japanese and Indian mulberry (Morus spp.) genotypes revealed by DNA fingerprinting. Plant Systemat. Evol. 243: 221-232.

Wang YJ, Li XY, Han J, Fang WM, et al. (2011). Analysis of genetic relationships and identification of 54 flowering-mei cultivars using EST-SSR markers developed from apricot and fruiting mei. Sci. Hortic. 132: 12-17.

Williams JG, Kubelik AR, Livak KJ, Rafalski JA, et al. (1990). DNA polymorphisms amplified by arbitrary primers are useful as genetic markers. Nucleic Acids Res. 18: 6531-6535.

Yang YJ, Zhang KC and Lin K (2002). Studies on RAPD polymorphisms and genetic relationship of Prunus persica plants. J. Henan Agric. Univ. 36: 187-189.

Yonemoto Y, Chowdhury AK, Kato H and Macha MM (2006). Cultivars identification and their genetic relationships in Dimocarpus longan subspecies based on RAPD markers. Sci. Hortic. 109: 147-152.

Yuan Z, Luo LS, Xiao DX and Zhang DB (2002). A study on the genetic relationship of peach species using RAPD markers. Acta Agric. Univ. Jiangxiensis 24: 172-175.

Zhang XY, Qian JL, Wang HK, Yuan WM, et al. (2011). A novel strategy employed in identification of 25 important loquat cultivars using RAPD marker. Caryologia 64: 265-271.

Zhao MZ, Zhang YP, Wu WM, Wang C, et al. (2011). A new strategy for complete identification of 69 grapevine cultivars using random amplified polymorphic DNA (RAPD) markers. Afr. J. Plant Sci. 5: 273-280. 